\title{
Experimental Researching of Dynamic Quality and Safety Movement of Half-Wagons which have Trolleys with Diagonal Connections
}

\author{
${ }^{1}$ Yerzhan Adilkhanov, ${ }^{1}$ Maral Murzakayeva, ${ }^{1}$ Nurlan Igembayev, ${ }^{2}$ Algazy Zhauyt \\ ${ }^{3}$ Toty Buzauova, ${ }^{1}$ Gabit Bakyt and ${ }^{4}$ Seitzhan Orynbayev \\ ${ }^{1}$ Kazakh Academy of Transport and Communications named after M. Tynyshpayev, \\ 050012 Almaty, Kazakhstan \\ ${ }^{2}$ Almaty University of Power Engineering and Telecommunications, 050013 Almaty, Kazakhstan \\ ${ }^{3}$ Karaganda State Technical University, 100000 Karaganda, Kazakhstan \\ ${ }^{4}$ Taraz State University named M.Kh. Dulaty, 080012 Taraz, Kazakhstan
}

\begin{abstract}
This study is dedicated for experimental studies of dynamic qualities of movement and safety of half-wagons trolleys with diagonal connections operated on the territory of the Republic of Kazakhstan. The main results of the study obtained from testing gondolas on trucks with diagonal ties as they move on straight and curved track sections as well as turnouts. An assessment of the safety factor against the gathering wheel rail lateral forces transmitted from the wheel on the rail the relationship of forces to the frame static load from wheel pairs on rails and smooth progress indicator.
\end{abstract}

Key words: Trolleys 18-100 (CNII-X3), dynamic qualities, wagon dynamics, trolleys 18-9996 (ZK-1), assessment, transmitted

\section{INTRODUCTION}

On the railways of the Republic of Kazakhstan, the Russian Federation and other countries of the Commonwealth of Independent States, freight wagons are mainly used on trolleys 18-100 (CNII-X3), designed according to the standards of the way content of 1950 , tested in 1952 and produced serially from 1956 till the present (Orlova, 2008). For freight wagons on CNII-X3 trolleys, the characteristic position when moving in a circular curve is the contact of the first wheel pair with the rail external to the curve of the ridge (Scheffel, 1974; $1975 ; 1981)$. In this case, not only the natural rotation of the trolleys under the car body is observed but also an undesirable phenomenon called "running" (or "overtaking") of the side frames in the curve when the truck adopts the parallelogram configuration in the plan (Wickens, 2003). If the trolley is significantly skewed, contact may also occur with the ridge of the inner wheel of the second wheel pair of the trolley. This position of the trolley in the rail track was called the jammed wedge (Karibzhanov, 2009). The geometry of the carriages of the freight wagon when it moves in a circular curve leads to the fact that the reaction to the inertia force acting on the crew is concentrated in the contact crest of the outer wheel of the first wheel pair with the rail (Blokhin et al.,
2012). A large value of the transverse force acting between the wheel and the rail can lead to the lifting of the wheel and the wagon from the rails (Solonenko and Makhmetov, 2017). Increased safety of movement in the curve is possible by redistributing the inertia force of the crew between all the outer wheels (Adilkhanov et al., 2017). This is possible if the crew's wheel sets occupy a radial position in the circular curve (Boronenko and Orlova, 2008). At angles of approach of a wheel pair on a rail no more than $5 \mathrm{mrad}$, the entry of a bogie into a curve is considered to be close to a radial one (Kossov et al., 2008).

Experience shows that the main way to reduce the running of the side frames relative to each other and to ensure the self-centering wheel sets in curved sections road is the equipment of the carriages with additional connections (Kharybin et al., 2009). Theoretical foundations for the creation of trolleys with self-centering wheel sets were laid by Wickens and Scheffel. This includes the trolley model 18-9996 (ZK-1) which since, 2008 is in operation on the railways of the Republic of Kazakhstan (Fig. 3).

\section{MATERIALS AND METHODS}

The main difference between the trolley model 18-9996 (ZK-1) and the main models of three-element

Corresponding Author: Yerzhan Adilkhanov, Kazakh Academy of Transport and Communications named after M. Tynyshpayev, 050012 Almaty, Kazakhstan 


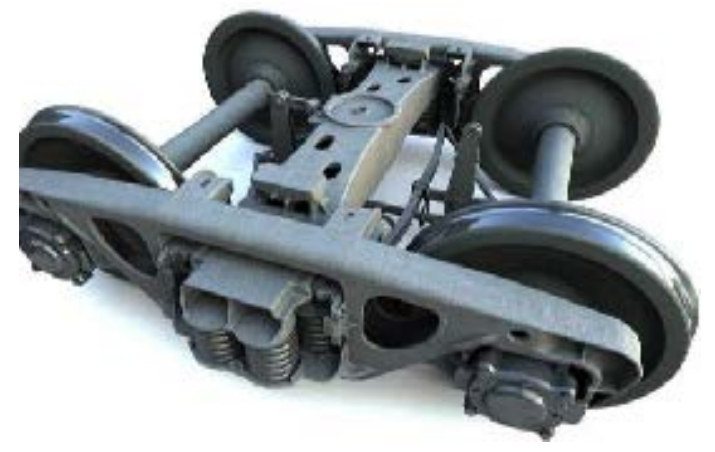

Fig. 1: Model trolleys 18-100 (CNIIX3)

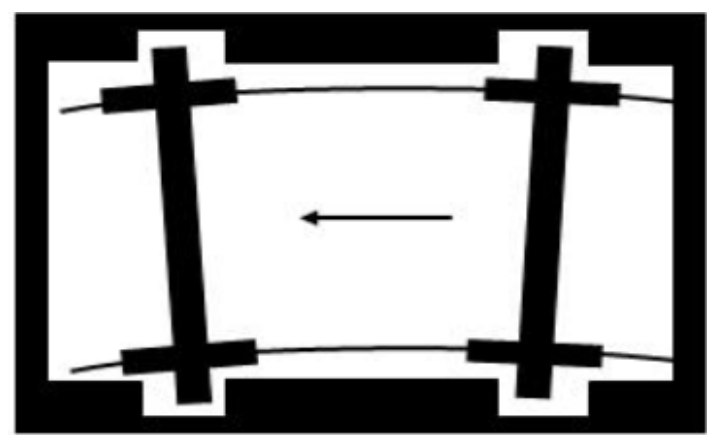

Fig. 2: Radial arrangement of wheel pairs in the curve

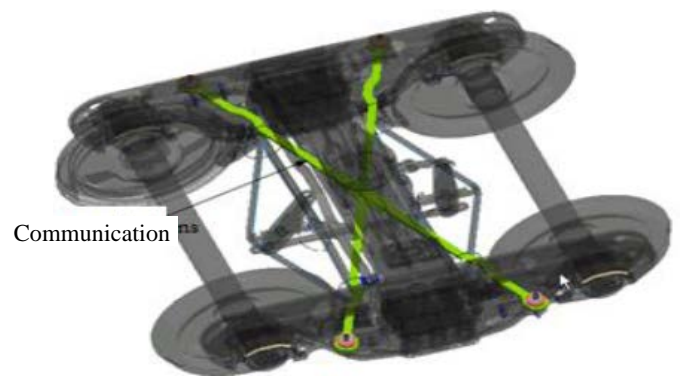

Fig. 3: Model trolleys 18-100 (CNII-X3) and 18-1999 (ZK-1)

trolleys is the presence of diagonal joints between the side frames which increase the longitudinal stiffness of the trolley in plan and accordingly reduce the longitudinal running of the side frames relative to each other and provide self-centering in the curved sections. As a result, the intensity of cart wagging decreases and the smoothness of the wagon progress improves (Fig. 1-3).

The first tests of wagons with these trolleys were conducted in November 2011 on the railways of the Republic of Kazakhstan by the Industry Research Laboratory of Dynamics and Strength of Rolling Stock of Dnipropetrovsk National University of Railway Transport

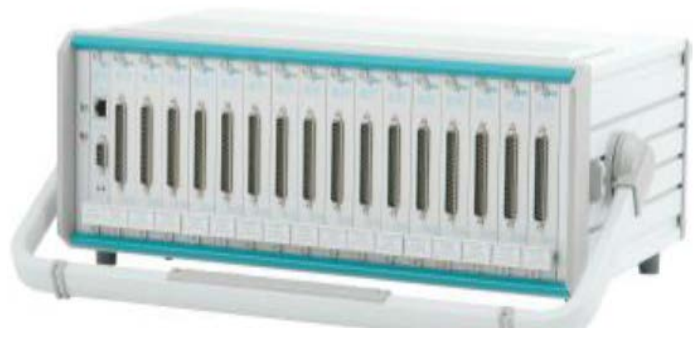

Fig. 4: Universal portable multi-channel measuring and computing system MIC-0.36

named after academician V. Lazaryan. In addition, study gives the results of testing cars on trolleys with diagonal links. However, the papers are of an overview nature, test methods are not given, not all evaluation indicators are analyzed which makes it impossible to draw unequivocal conclusions to assess the degree of influence on the railway track and the safety of wagons on trolleys model 18-9996 (ZK-1).

In this connection, the researchers of this study analyzed the results of experimental studies conducted in 2016 on the straight, curved sections of the track and on the $=$ crosspoints with cross marks of grades $1 / 9$ and $1 / 11$. The tests were carried out using modern measuring equipment. To record and analyze vibration, displacements and mechanical stresses, a multichannel measuring complex (crate) was used for the production of the MERA research and production enterprise (Rossiya) Fig. 4.

To measure the lateral and frame forces, the dynamic coefficients, single-type strain gauges with a resistance measurement range $100 \Omega$, a sensitivity of 2.10 and a base of $10 \mathrm{~mm}$. Accelero meters with a frequency range of $0.5, \ldots, 10000 \mathrm{~Hz}$ have been installed to determine the accelerations of the trolley and the body, the results of which were calculated for the smooth running.

Figure 5 shows the locations of sensors for recording processes to determine the dynamic performance of the half wagon. Where, Y frame force measuring circuit $\mathrm{KDI}_{\text {right }}, \mathrm{KDI}_{\text {left }}$. The scheme for measuring the vertical dynamics coefficients of the first (pedigree) stage KDII scheme for measuring the coefficient of vertical dynamics of the second (central) stage; $\mathrm{a}_{\mathrm{ZH}}, \mathrm{a}_{\mathrm{YH}}, \mathrm{a}_{\mathrm{ZV}}, \mathrm{a}_{\mathrm{YV}}$ acceleration of the frames of the trolley and body in horizontal and vertical directions when tested diverters forces transmitted by the wheels on the rails in the horizontal and vertical directions, measured in the anterior radius of frame rails and a transfer curve (Fig. 6). On the 


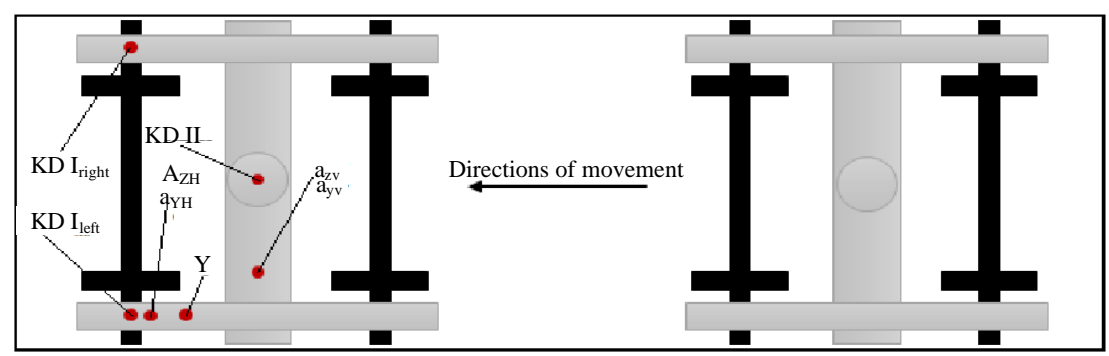

Fig. 5: Placement of sensors on the wagon

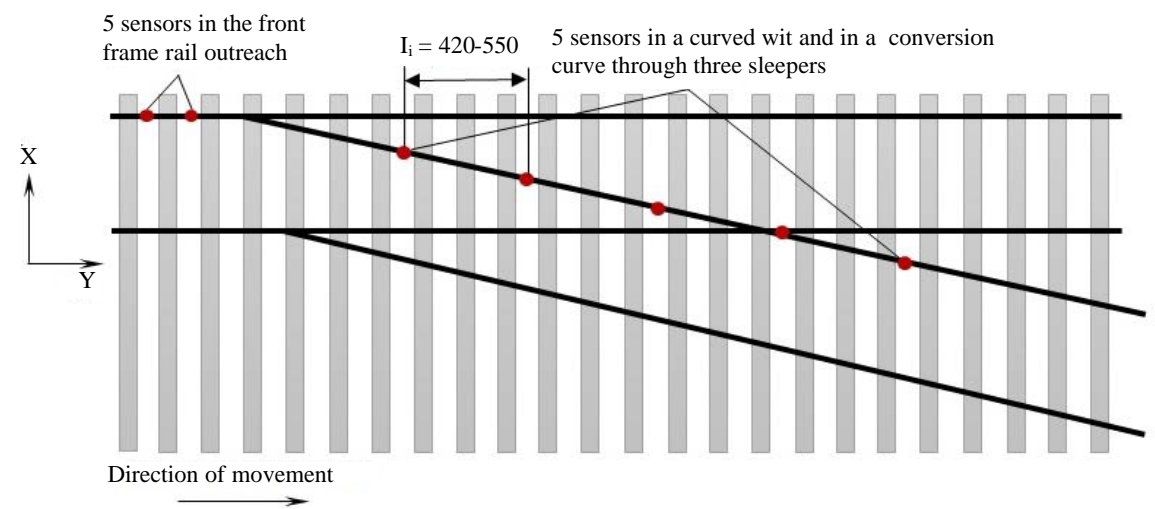

Fig. 6: Arrangement of sensors in switches

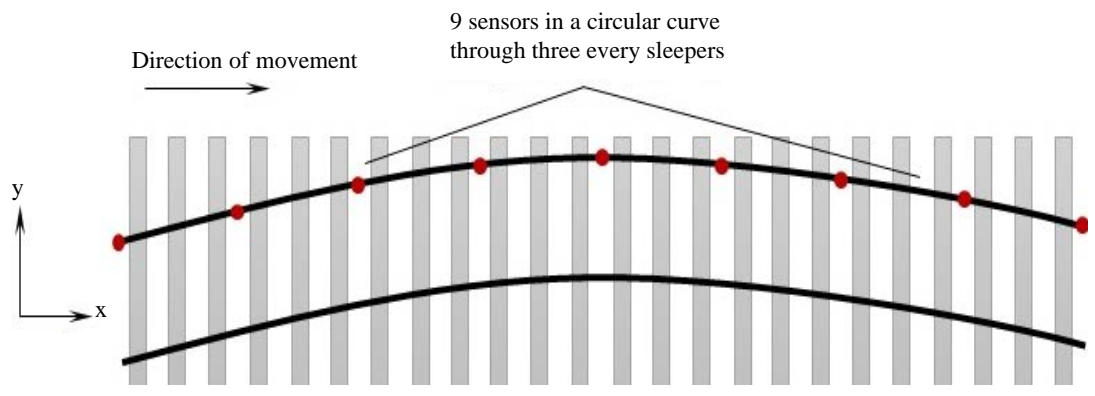

Fig. 7: A rrangement of sensors in a curved section

curved section, the sensors were glued on to the outer rail (Fig. 7). According to the results of data processing at a given speed, separate data sets were formed for each measuring circuit.

According to these arrays there were estimated values of the indicators. All measurements were broken according to speeds (Solonenko and Makhmetov, 2017). In each run, one maximum amplitude value of the dynamic process was selected. As evaluative indicators, side forces, frame forces to the static load from the wheel pair to the rails, the stability criterion of the rail-shear lattice from the shear, the stability factor against the wheel derailment from the rail and the smoothness index were adopted. In the test input, the dynamic coefficients, the verical forces from the wheel to the rails and the acceleration of the trolleys and wagons were measured but these indicators were used only for calculations.

To register the lateral forces from the wheel to the rails, a bridge circuit using the Schlumpf method was used in Fig. 8. To calibrate the strain-gauge circuits for measuring lateral and vertical forces, a special loading device with force-measuring sensors was used. The evaluation of the lateral forces was carried out only in the laden mode on the turnouts and the curved track section, since in the empty regime the lateral forces do not exert a strong influence on the path (Solonenko and Makhmetov, 2017). For each speed value the average value of the lateral force for each wheel pair is calculated by the Eq. 1: 

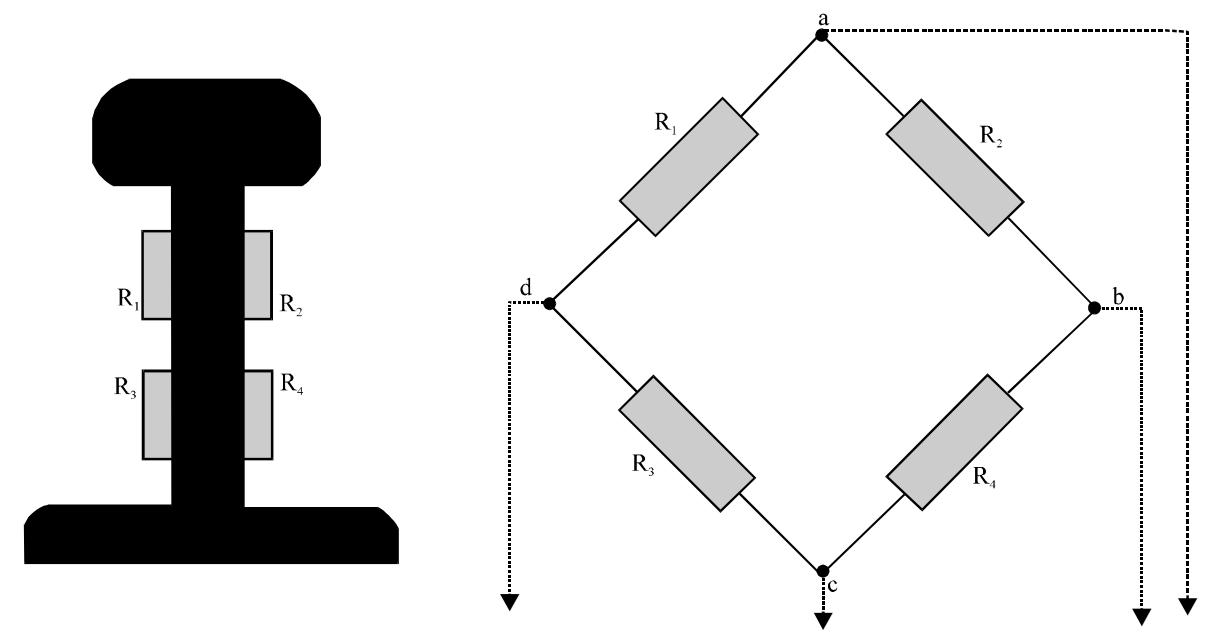

Fig. 8: Scheme of measurement of lateral forces on the neck of the rail by strain gages using the Schlumpf method

Table 1: Normative value of the indicators to be determined

Name defined characteristics

Allowable lateral forces transmitted from the wheel to the rail

In straight, curved and switch translations on wooden beams

In turnouts on reinforced concrete beams

The stability criterion of a rail-shear lattice from shear

The permissible ratio of the frame force to the vertical static

load of the wheel pair on the rails

Coefficient of stability against rolling off the rails

Ride indicator

$$
\mathrm{H}_{\mathrm{ka}}=\frac{\sum_{\mathrm{i}=1}^{\mathrm{n}} \sum_{\mathrm{j}=\mathrm{i}}^{\mathrm{k}} \mathrm{H}_{\mathrm{kij}}}{\mathrm{k} . \mathrm{n}}
$$

Where:

$\mathrm{H}_{\mathrm{kjj}}=$ Value of lateral force, registered

I $=$ Volume measurement on $\mathrm{j}-\mathrm{M}$ section

$\mathrm{n}=$ The number of measurements at a given speed in the selected direction of movement of the test object

$\mathrm{k}=$ Number of sections

The dispersion of the experimental data obtained in the measurement of lateral forces is calculated by the Eq. 2 :

$$
\mathrm{D}=\frac{1}{\mathrm{k}(\mathrm{n}-1)} \sum_{\mathrm{i}=1}^{\mathrm{n}} \sum_{j=1}^{\mathrm{k}}\left(\mathrm{H}_{\mathrm{kij}}-\mathrm{H}_{\mathrm{ka}}\right)
$$

The average quadratic deviation of the experimental data obtained in the measurement of lateral forces is calculated by the Eq. 3 (Table 1):

$$
\mathrm{S}=\sqrt{\mathrm{D}}
$$

Normative value (in brackets for empty wagons)

Not more $100 \mathrm{kN}$

Not more $120 \mathrm{kN}$

Not more 1.4

Not more $0.3(0.38)$

Not more 1.4

4.00

If it is possible to equalize the experimental distribution series by the theoretical laws of Gauss or Chebyshev-Hermite, the maximum probable value of the lateral forces is calculatedby the Eq. 4 :

$$
\mathrm{H}_{\mathrm{k}}=\mathrm{H}_{\mathrm{ka}}+2.5 \cdot \mathrm{S}
$$

Those registered processes and lateral force measurements are treated as random processes with the calculation of the maximum probable values with a probability of 0.994 . Thus, Fig. 9-11 show the dependence of the lateral forces transferred from the wheel to the rails on the speed of movement .

Analysis of the data which shown in Fig. 9-11 showed that the greatest side forces arise as a rule, from the influence of the steering wheel pairs in the trolley. In addition, during the observation it was revealed that the level of influence on the way of a laden half-wagon is 3-4 times higher than the level of exposure to the empty half-wagon. In the transfer curve of the switch gear with a crosspiece of grade $1 / 9$, there were recorded exceedances of the permissible values of lateral forces during the movement of a loaded half wagon at a speed of $50 \mathrm{~km} / \mathrm{h}$ (Fig. 9 on the left in red). When the loaded half wagon was moving at a speed of $40 \mathrm{~km} / \mathrm{h}$, 

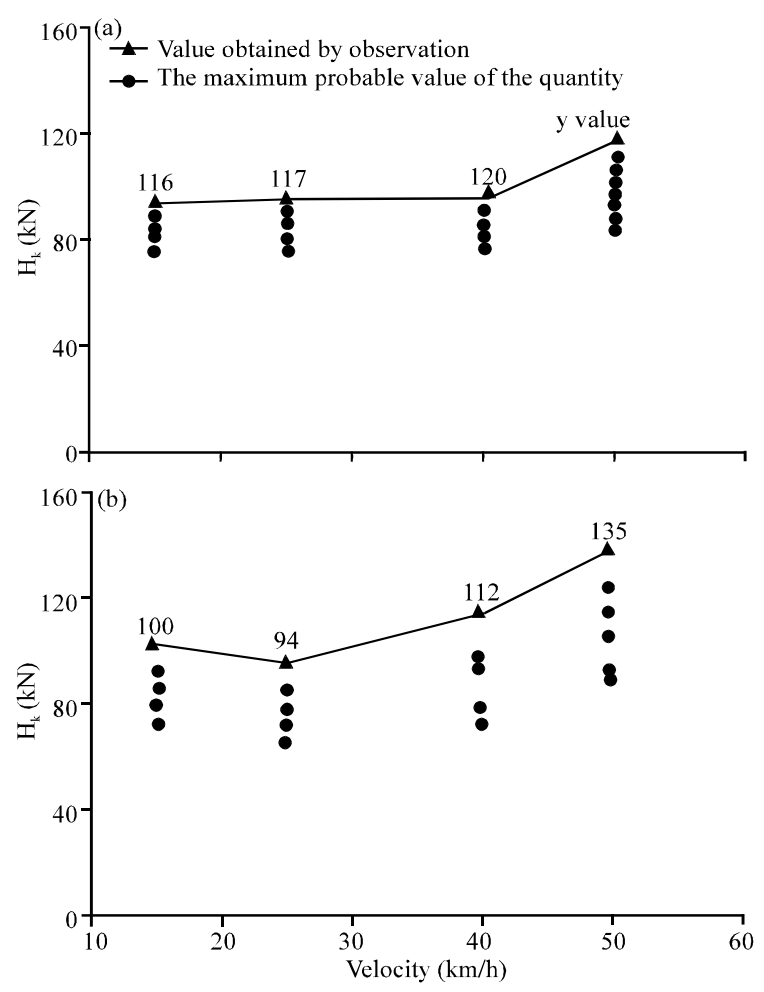

Fig. 9: Lateral forces from the wheel pair to the rails for; a) The arrow $1 / 9$ conversion curve and b) The frame rail

lateral forces reached the maximum permissible values. In this regard, it is recommended to limit the permissible speed of movement of a laden half wagon model on turnouts with a $1 / 9$ cross in the lateral direction to a speed of $35 \mathrm{~km} / \mathrm{h}$.

When moving on turnouts with cross marks $1 / 9$ and $1 / 11$ in the forward direction, the excess of impact indicators on the track was not revealed. Further, by calculation method, the values of the stability criterion of the rail-shear lattice from the lateral shear over ballast were determined which is estimated by the values of the ratio of the maximum horizontal load to the average vertical load of the rail on the tie and calculated according to the equations according to Table 2 and 3 :

$$
\alpha=\frac{\mathrm{H}_{\mathrm{k}}^{\max }}{\mathrm{P}_{\mathrm{V}}}
$$

Calculations showed that when moving along turnouts with cross marks $1 / 9$ and $1 / 11$ in the lateral direction at a speed of $50 \mathrm{~km} / \mathrm{h}$, the permissible value of the stability criterion of the rail-shear stability from the
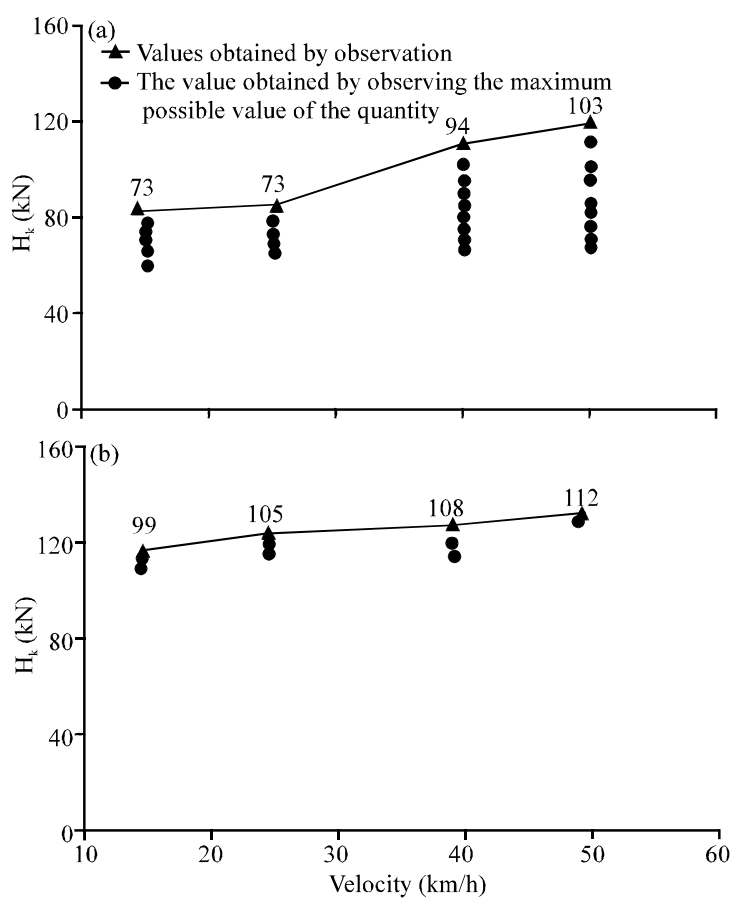

Fig. 10: Lateral forces from the wheel pair to the rails for; a) The arrow $1 / 11$ transfer curve and b) frame rail

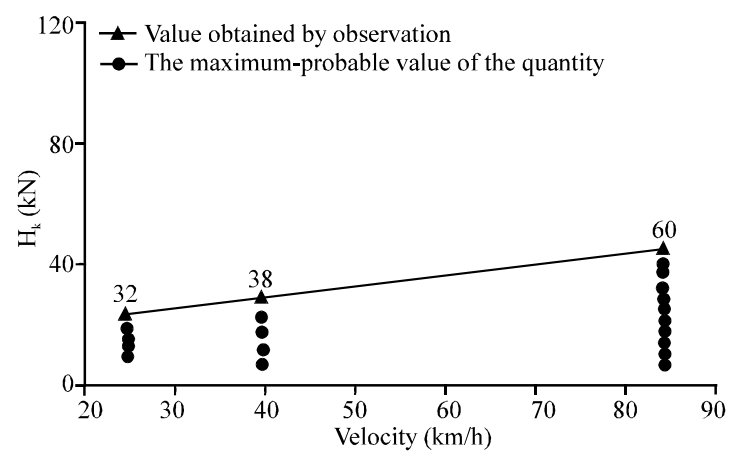

Fig. 11: Lateral forces from the wheel pair to the rails for the curved section

lateral shear over ballast (highlighted in red) was detected. When driving at a speed of $40 \mathrm{k} / \mathrm{h}$ and no excess was detected. When driving along the curve and the straight sections of the road, no excess was detected. The frame forces were determined using strain gauges for measuring dynamic stresses in the cross-sections of the trolley frames most sensitive to the action of lateral forces occurring in the frame of the trolley with the wheel pair as shown in Fig. 12. The frame forces were registered along the front (inbound) and last in the direction movement of the 
Table 2: Results of the calculation of the stability criterion of the rail-shear lattice from the transverse shear along the ballast in the turnout with the $1 / 9$

\begin{tabular}{|c|c|c|c|c|c|c|c|c|}
\hline \multirow[b]{2}{*}{ Empty $/$ Speed $(\mathrm{km} / \mathrm{h})$} & \multicolumn{4}{|c|}{ Wheel pair numbers } & \multicolumn{4}{|l|}{ Laden } \\
\hline & 1 & 2 & 3 & 4 & 1 & 2 & 3 & 4 \\
\hline 15 & 1.33 & 0.51 & 1.39 & 0.53 & 1.31 & 0.86 & 0.84 & 0.80 \\
\hline 25 & 1.15 & 0.64 & 1.35 & 0.65 & 1.25 & 0.80 & 0.68 & 0.84 \\
\hline 40 & 1.26 & 0.63 & 1.38 & 0.63 & 1.32 & 0.93 & 1.03 & 0.66 \\
\hline 50 & 1.82 & 0.58 & 1.95 & 0.75 & 1.32 & 0.95 & 1.11 & 0.83 \\
\hline
\end{tabular}

Table 3: Results of the calculation of the stability criterion of the rail-shear lattice from the transverse shear along the ballast in the turnout with the cross mark $1 / 11$

\begin{tabular}{|c|c|c|c|c|c|c|c|c|}
\hline \multirow[b]{2}{*}{$\begin{array}{l}\text { Speed }(\mathrm{km} / \mathrm{h}) \\
\text { Empty }\end{array}$} & \multicolumn{4}{|c|}{ Wheel pair numbers } & \multicolumn{4}{|c|}{ Laden } \\
\hline & $\begin{array}{l}--- \\
1\end{array}$ & 2 & 3 & 4 & 1 & 2 & 3 & 4 \\
\hline 15 & 1.31 & 0.66 & 1.39 & 0.49 & 1.05 & 0.40 & 0.85 & 0.41 \\
\hline 25 & 1.19 & 0.71 & 1.31 & 0.64 & 1.00 & 0.40 & 0.84 & 0.47 \\
\hline 40 & 1.38 & 0.63 & 1.38 & 1.03 & 1.26 & 0.54 & 1.03 & 0.58 \\
\hline 50 & 1.83 & 0.66 & 1.58 & 0.86 & 1.14 & 0.50 & 0.98 & 0.47 \\
\hline
\end{tabular}

Bold values are significnats values

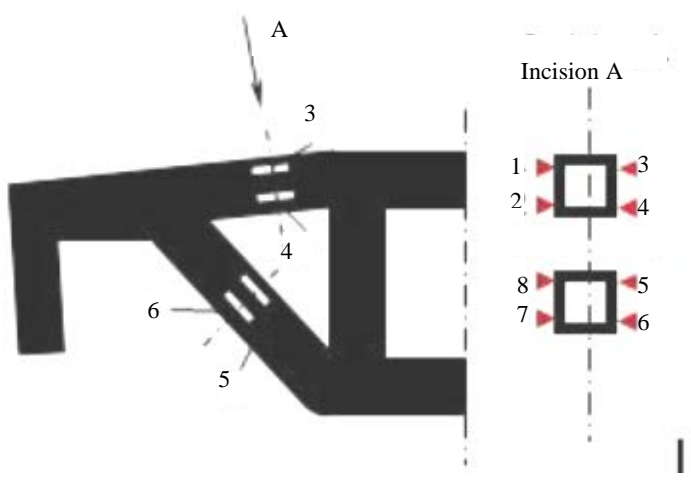

Fig. 12: Schemes of sticking strain gages on the side frame of the trolley for determining the frame forces through the measurement of stresses

half-wagon wheels. The values of the ratio of the frame force to the vertical static load of the wheel pair on the rails arecalculated from the maximum observed values of frame force realizations recorded at the same speed including taking into account quasi-static components caused by the action of centrifugal or centripetal forces on a unit of the railway rolling stock.

Dependences of the ratio of the frame forces to the static load from the wheel pair on the rails on the speed of movement are given in Fig. 13 and 15 (where are the values obtained by observation $\_$the maximum-probable value of a quantity, $\mathrm{H}_{\mathrm{k}}^{\mathrm{p}}=\mathrm{H}_{\mathrm{ka}}^{\mathrm{p}}+3 \mathrm{~S}, \mathrm{H}_{\mathrm{ka}}^{\mathrm{p}}$ the average value of the frame force for the corresponding speed, S-Standard deviation of force).

It can be seen from Fig. 13-15 that the ratio of the frame forces to the static load from the wheel pair to the rails during the movement of open wagons in the case of turnouts is within the permissible values. There is also a noticeably greater dynamics in the empty car. Then, on the instantaneous values of the frame forces and the coefficient vertical dynamics of the first stage of spring
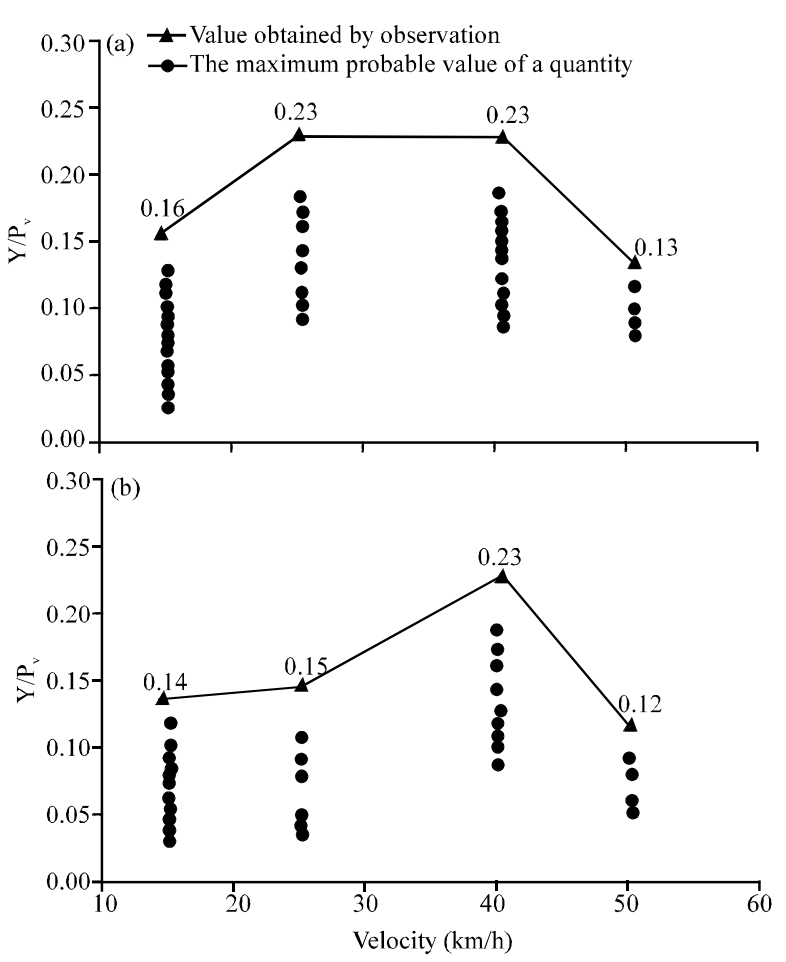

Fig. 13: The ratio of the frame forces to the static load from the wheel pair to the rails for; a) The 1/9 half wagon in the empty and b) Laden states

suspension, the values safety factor of stability against the derailment of the wheel from the rail were calculated according to the Eq. 6 (Fig.16):

$$
\mathrm{K}_{\mathrm{saf}}=\frac{\operatorname{tg} \beta-\mu}{\mu \cdot \operatorname{tg} \beta+1} \cdot \frac{\mathrm{P}_{\mathrm{v}}}{\mathrm{H}_{\mathrm{k}}} \geq[1,4]
$$

Where:

$\mu=$ Coefficient of friction between the ridge of the approaching wheel and the rail 


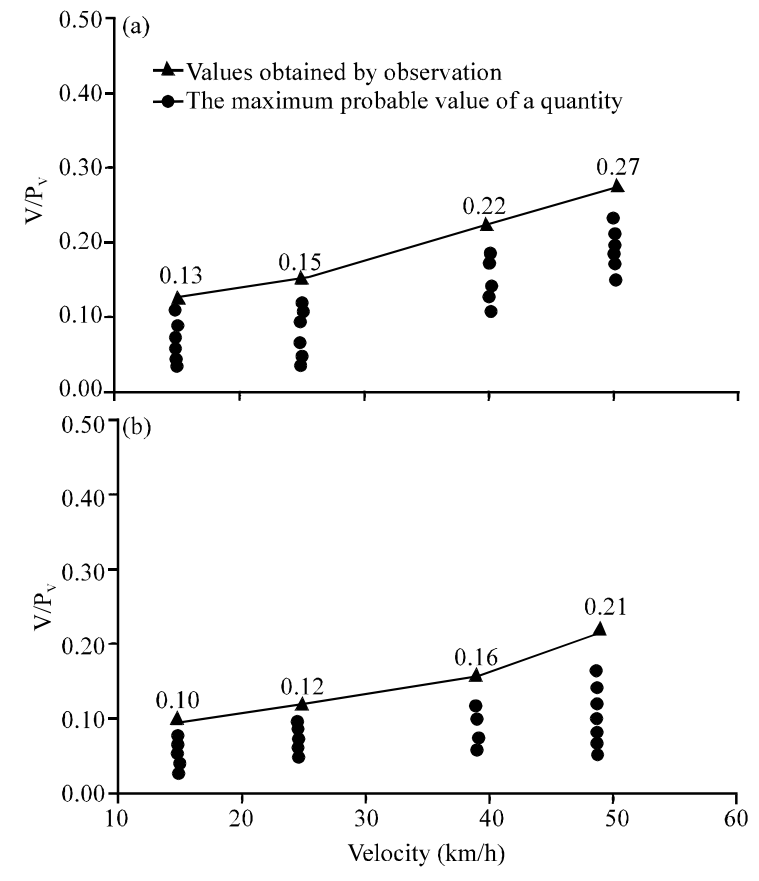

Fig. 14: The ratio of the frame forces to the static load from the wheel pair to the rails for; a) The 1/11 half-wagon in the empty and b) Laden states
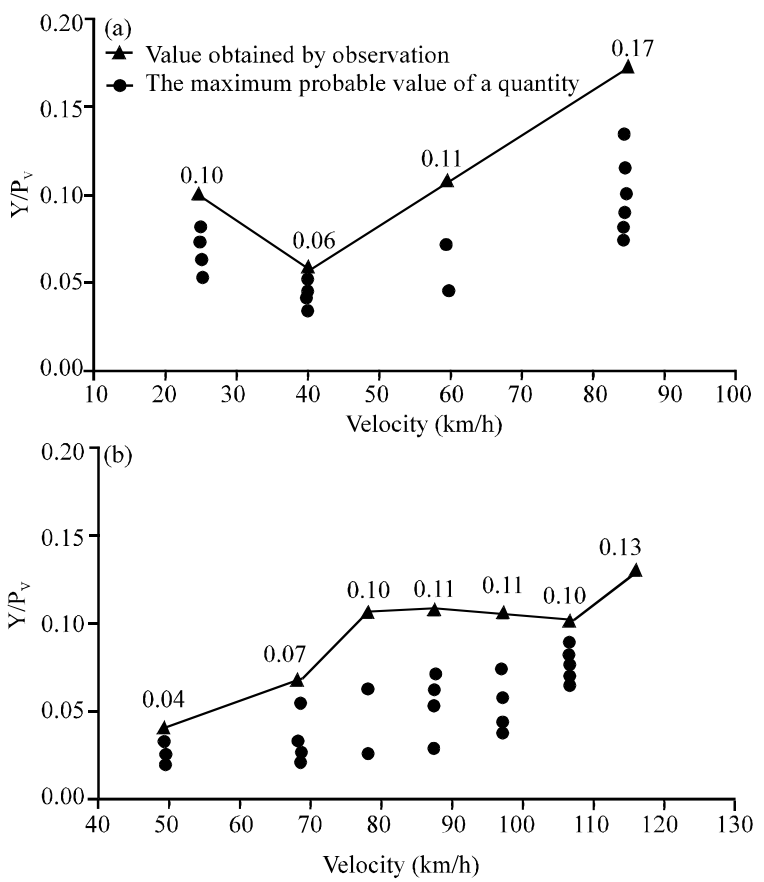

Fig. 15: a, b) The ratio of the frame forces to the static load from the wheel pair on the rails of the laden gondola car for the curve (on the left) and the straight (on the right)

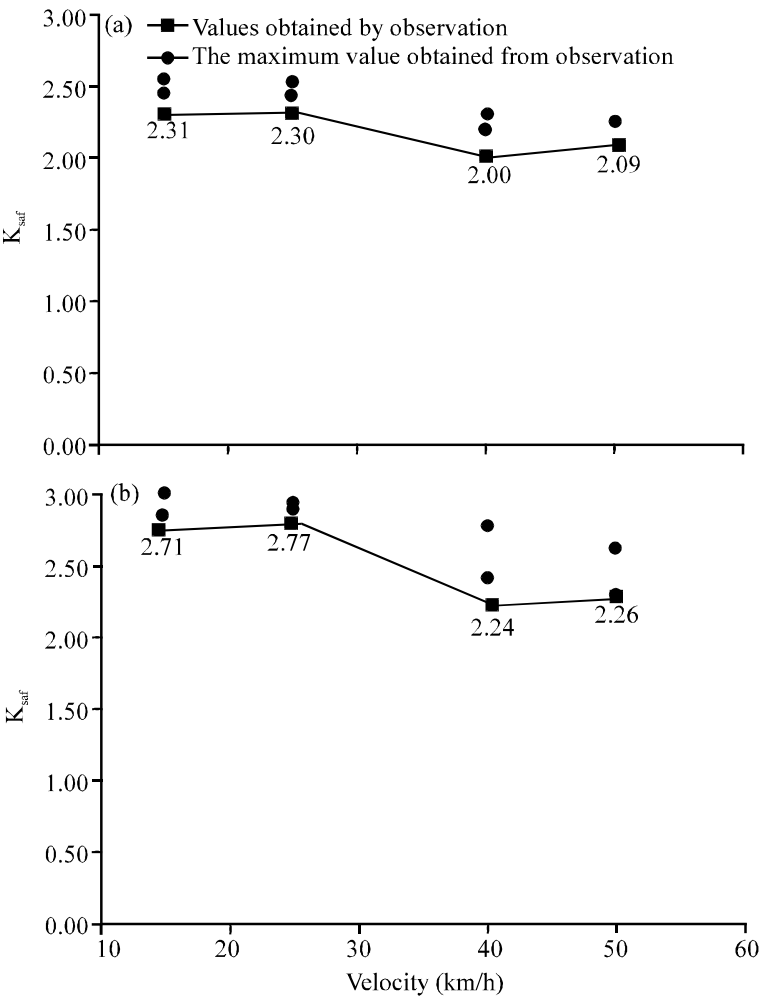

Fig. 16: a, b) Coefficient of stability margin against the derailment of the wheel from the rail when passing an empty gondola car of the turnout 1/9 (left) and $1 / 11$ (on the right)

$\beta=$ Angle of inclination of the generatrix of the ridge of the wheel to the horizontal plane, $\beta=60^{\circ}$

$\mathrm{P}_{\mathrm{V}}=$ Vertical load from wheel to rail

$\mathrm{H}_{\mathrm{k}}=$ Lateral force from wheel to rail

\section{RESULTS AND DISCUSSION}

The stability factor was estimated at the minimum calculated value only in the empty mode (Fig. 16 and 17). The following symbols are used in the figures: $\rightarrow$ values obtained by observation; - the minimum value obtained from observation. The dependencies shown in Fig. 16 and 17 show that the stability factor against the derailment of the wheel from the rail when passing the half-cars of turnouts on the side, the curve and the straight sections of the track are within the permissible limits, i.e., take values of at least 1.4. At the next stage, according to the accelerometer readings, mounted on the box of half wagon, calculation of the smoothness indicators for a straight section of the track was made. The results are shown in Fig. 18 and 19. The results shown in Fig. 18 and 19 show that the smoothness 

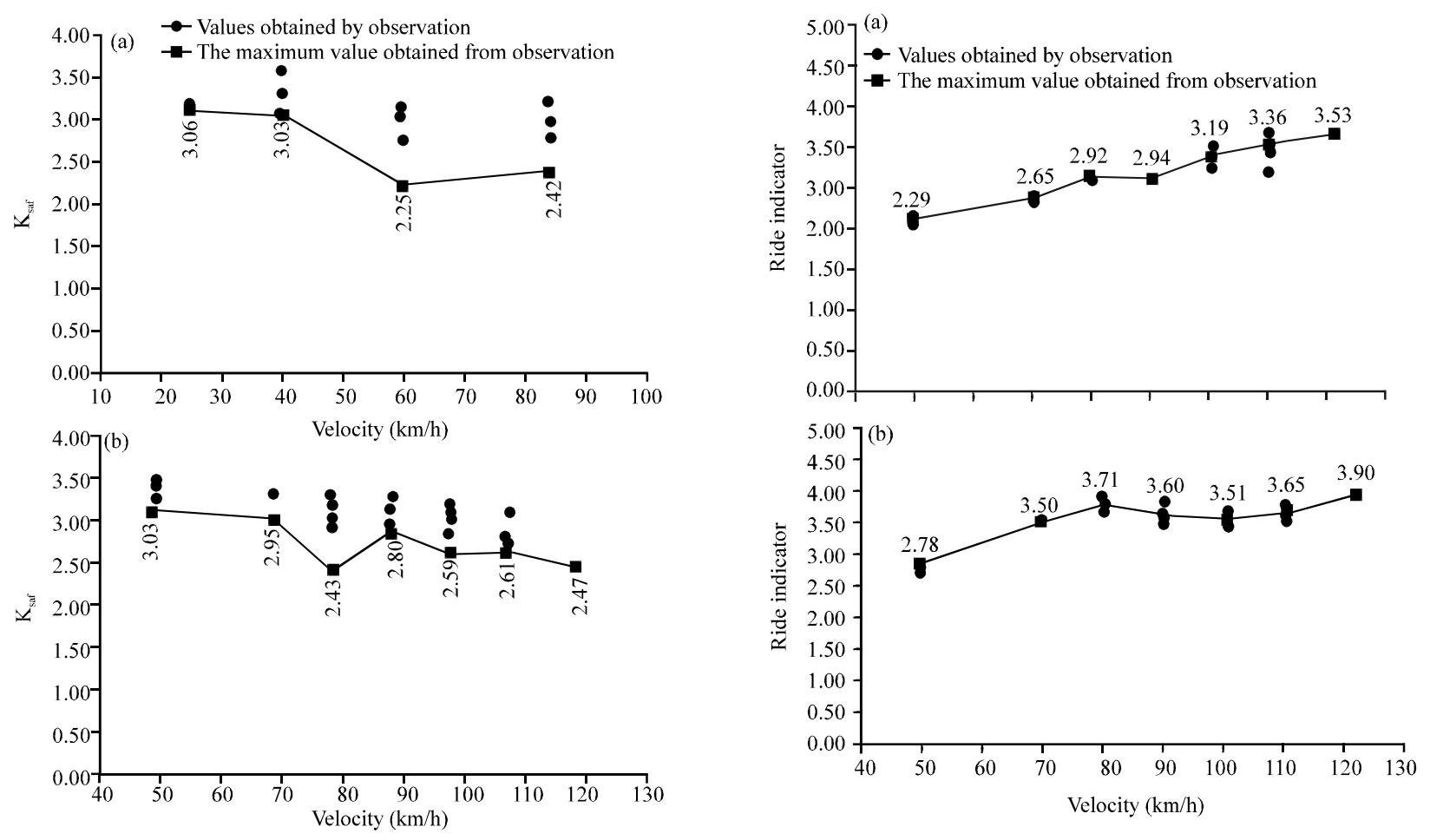

Fig. 17: a, b) Stability factor of the stability against the derailment of the wheel from the rail when passing an empty gondola car (left) and straight (right)

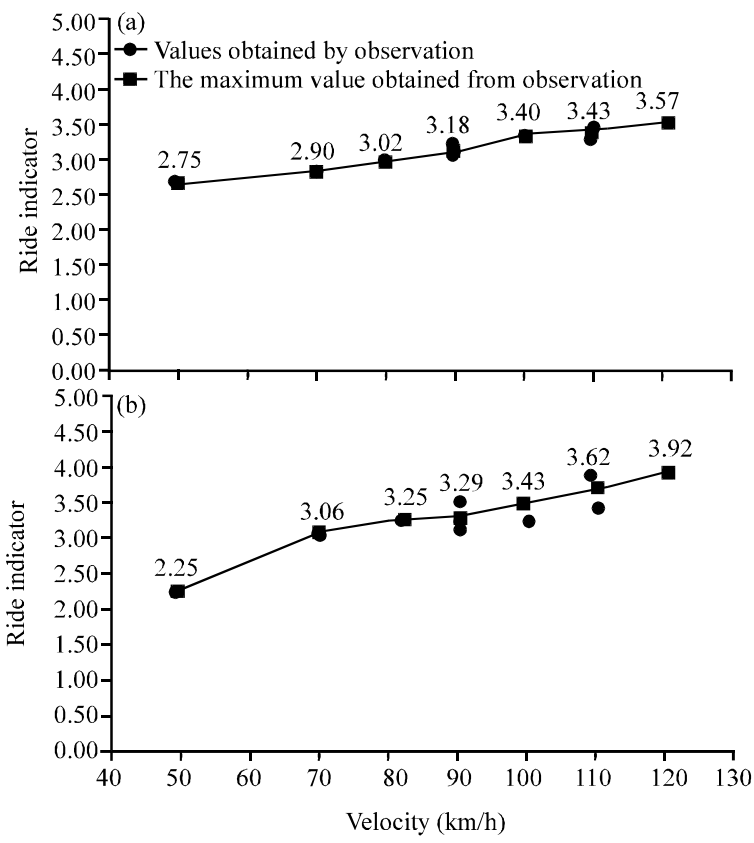

Fig. 19: Indicators of the smoothness of the laden half wagon on the direct route; a) Horizontal direction and b) Vertical direction

indicators of half wagons on straight sections of the road meet the requirements for driving at speeds up to structural.

\section{CONCLUSION}

The analysis of the results dynamic driving and the impact on the way and turnouts tests of a half wagon truck equipped with carts with diagonal connections made it possible to draw the following conclusions. The value ratio of the frame forces to the static load from the wheel pair to the rails and the safety factor against the derailment of the wheels from the rail in turnouts with rails of type $\mathrm{P} 65$ of grade $1 / 9$ and $1 / 11$ to a speed of $40 \mathrm{~km} / \mathrm{h}$ in a curve with a radius of $400 \mathrm{~m}$ and The straight section of the road meets regulatory requirements lateral forces on the turnout with a $1 / 9$ crosspiece when moving a loaded half wagon in the lateral direction at a speed of $50 \mathrm{~km} / \mathrm{h}$ exceed the normative value by $20 \%$. In this regard, it is recommended to limit the permissible speed of movement of a laden gondola model on turnouts with a 1/9 cross in the lateral direction to a speed of $35 \mathrm{~km} / \mathrm{h}$. The criterion for the stability of the rail-shear lattice from transverse shear over ballast in all the experimental sections does not exceed the normative values. He dynamic line load on the way meets the requirements of the established norms direction and b) Vertical direction 
smoothness indicators of the half wagon comply with the regulatory requirements when driving at speeds up to structural. Proceeding from all the above, it can be concluded that in general half wagons equipped with trolleys with diagonal connections between side frames have improved dynamic qualities and can be admitted to operation on the main roads of the countries of the common wealth of independent States.

\section{REFERENCES}

Adilkhanov, Y., S. Sekerova, J. Musayev, A. Zhauyt, A. Auezova and G. Smailova, 2017. Simulation technique of constant contact side bearings of freight car bogies. J. Measur. Eng., 5: 142-151.

Blokhin, E.P., K.T. Alpysbaev and R.B. Granovsky, 2012. Dynamic qualities of freight wagons having trolleys with diagonal links. ??ch. Sci. Nat. UNTU. ??, 5: 12-16.

Boronenko, Y.P. and A.M. Orlova, 2008. Trolleys with increased axial load. Railway Transp., 10: 50-53.

Karibzhanov, E., 2009. Freight wagons of Kazakhstan: We improve the technical condition. Wagons Carload Wagons, 4: 34-35.

Kharybin, I.A., A.M. Orlova and A.V. Dodonov, 2009. To improve the running gear of freight cars. Cars Facil., 2: 26-29.
Kossov, V.S., V.A. Charkin and L.K. Dobrynin, 2008. A trolley with an axial load of 25 tons for a freight wagons of a new generation. Railway Transp., 7: 55-58.

Orlova, A.M., 2008. Influence of constructive schemes and parameters of trolley on stability, driving qualities and loading of freight wagons. MSc Thesis, Saint Petersburg State University, Saint Petersburg, Russia.

Scheffel, H., 1979. The influence of the suspension on the hunting stability of railways. Rail Intl., 10: 662-696.

Sheffel, H., 1974. Stability in wagging with a lateral attitude and the ability of rolling stock to fit into curves. Railways World, 12: 32-46.

Sheffel, H., 1975. New construction of suspension of railroad cars. Railways World, 4: 15-22.

Sheffel, H., 1981. The influence of suspension on the stability of rolling stock with a tortuous motion. Railways World, 5: 10-32.

Solonenko, V.G. and N.M. Makhmetov, 2017. Dynamic characteristics of freight wagons produced by LLP KVK on trolleys model 18-9996. J. Dynamic Sci., 3: 54-60.

Wickens, A.H., 2003. Fundamentals of Rail Vehicle Dynamics: Guidance and Stability. Swets \& Zeitlinger Publishers, Lisse, Netherlands, ISBN:9789026519468, Pages: 282. 